\title{
The Effect of Problem-Based Learning on Metacognitive Ability in the Conjecturing Process of Junior High School Students
}

\author{
Sutarto $\left(\mathbb{D},{ }^{1}\right.$ Intan Dwi Hastuti $\left(\mathbb{D},{ }^{2}\right.$ Doris Fuster-Guillén $\left(\mathbb{D},{ }^{3}\right.$ Jessica Paola Palacios Garay $\left(\mathbb{D},{ }^{4}\right.$ \\ Ronald M. Hernández $\mathbb{D}, 5$ and Ehsan Namaziandost $\mathbb{D}^{6,7}$ \\ ${ }^{1}$ Mathematics Education, Engineering and Applied, Universitas Pendidikan Mandalika, Kota Mataram, Indonesia \\ ${ }^{2}$ Elementary School Teacher Education, Universitas Muhammadiyah Mataram, Kota Mataram, Indonesia \\ ${ }^{3}$ Universidad Nacional Mayor de San Marcos, Lima, Peru \\ ${ }^{4}$ Universidad Norbert Wiener, Lima, Peru \\ ${ }^{5}$ Unidad de Virtualización Académica, Universidad de San Martín de Porres, Lima, Peru \\ ${ }^{6}$ University of Applied Science and Technology (UAST), Khuzestan, Ahvaz, Iran \\ ${ }^{7}$ Mehrarvand Institute of Technology, Abadan, Iran
}

Correspondence should be addressed to Ehsan Namaziandost; e.namazi75@yahoo.com

Received 27 September 2021; Accepted 22 December 2021; Published 12 January 2022

Academic Editor: Gwo-Jen Hwang

Copyright (C) 2022 Sutarto et al. This is an open access article distributed under the Creative Commons Attribution License, which permits unrestricted use, distribution, and reproduction in any medium, provided the original work is properly cited.

This study aimed to analyze the effect of problem-based learning on metacognitive abilities in the conjecturing process of junior high school students. To reach this purpose, a mixed-methods design, which is a combination of quantitative and qualitative methods, was used. The quantitative method was used to analyze the metacognitive abilities of the students' conjecturing process, while the qualitative method was used to explore observation and interview data. The subjects of this study consisted of 60 eighthgrade students. Two learning models were compared, namely the problem-based learning model and the conventional learning model. The metacognitive abilities of students' conjecturing process were measured by a pattern generalization problem-solving test. After collecting the data and analyzing them through the independent-samples $t$-test, it was revealed that the PBL had a significant effect on the metacognitive abilities of students' conjecturing process in solving pattern generalization problems. Finally, based on the results, some conclusions and implications were suggested.

\section{Introduction}

Metacognitive studies have become a crucial issue discoursed in the educational division recently $[1,2]$. Metacognitive abilities are an indicator emphasized in achieving learning goals because they can encourage higher-order thinking skills. It also involves student activeness, building students to be independent, asking well, seeking answers to questions, and finding answers independently [3-5]. Metacognitive ability is a part of higher-order thinking skills and refers to controlling, monitoring, and self-regulating activities while learning and solving problems $[6,7]$. With metacognitive abilities, students can manage their involvement in assignments and seek to optimize learning processes and outcomes. For example, when students face obstacles in solving problems, they are able to rethink and revise according to the target task objectives [3]. It is in line with Anderson and Krathwohl [8], who define three indicators of metacognitive abilities, namely (1) planning, (2) evaluation, and (3) monitoring.

Students' metacognitive abilities can be seen from the students' ability to solve any problems faced in everyday life. Metacognition is closely related to problem-solving. Metacognition arises when a person encounters an unknown problem, uncertainty, question, or dilemma [9]. With metacognition, students can solve their problems because they recognize problems that need to be resolved, see the problem, and understand how to achieve goals or solutions [4].

Problem-solving is an important issue in constructivist learning. Regarding content standards for primary and 
secondary education, the Minister of Education and Culture in 2013 believed that problem-solving is part of the knowledge competencies that must be possessed by the eleventh-grade students. According to, problem-solving is the center of inquiry and application that should be embodied in the mathematics curriculum to provide a context for learning and application of mathematical ideas. Problem-solving plays an important role in the curriculum for several reasons: (1) it can build new mathematical knowledge, (2) it can solve problems that arise in mathematics and in other contexts, (3) it can apply and adapt various problem-solving strategies, and (4) it can monitor and reflect on the process of solving mathematical problems.

Some previous studies have revealed that students' metacognitive skills in Indonesia are still at the lowest level [3, 10-12]. Even the metacognitive abilities of elementary school teacher candidates are still at a low level [13]. This fact is very sad because the metacognitive activity is a strong indicator of a person's cognitive development and a determinant in achieving learning goals, so this problem needs to be found a solution.

One of the factors that cause students' low metacognitive abilities is learning activities designed in the form of teachercentered activities and activities emphasized on cognitive aspects. In addition, metacognition is closely related to problem-solving. Metacognition occurs when a person encounters unknown problems, uncertainties, questions, or dilemmas.

One of the mathematical problems associated with metacognition activities is the problem of pattern generalization $[13,14]$. Pattern generalization is an important aspect of mathematics contained in every topic and is something that is highlighted in teaching at almost all levels [15]. According to Kuchemann, generalization must be the core of mathematical activities in schools [16].

In solving the problem of pattern generalization, a conjecturing process occurs. The conjecturing process is a mental activity in building conjectures. A conjecture is a statement about all possible cases based on empirical facts but with an element of doubt [17]. It is further explained that the stages of the conjecturing process are observing cases, organizing cases, looking for and predicting patterns, formulating conjectures, validating conjectures, generalizing conjectures, and justifying generalizations. In solving the problem of pattern generalization, a conjecturing process occurs. From that process, there is metacognitive activity.

One solution to improving students' metacognitive abilities is through student-centered learning activities such as problem-based learning. The problem-based learning (PBL) syntax directs students to think, analyze, research, and compile research reports. Problem-based learning has five syntaxes, namely (1) student orientation to the problem, (2) organizing students to learn, (3) guiding individual or group investigations, (4) developing and presenting work results, and (5) analyzing and evaluating problem-solving. The investigation stage, which is carried out independently or in groups, is at the core of the PBL model. Activities carried out by students at the investigative stage include the process of collecting data, making hypotheses, and providing solutions so that problemsolving skills can be developed and trained.

Previous studies have proven that PBL-based learning affects critical thinking skills, problem-solving, and writing skills [11, 18, 19]. PBL increases student self-confidence, creates a supportive environment for group work, improves interpersonal communication and critical thinking skills, and builds self-awareness [20,21]. PBL is a learning model in which relevant problems are introduced at the beginning of the learning cycle and are used to provide context and motivation for students $[22,23]$. PBL requires an active condition and usually involves various activities. According to Aldarmahi [20], PBL is useful for students in constructing knowledge, developing reasoning processes, improving independent learning skills, and increasing intrinsic learning motivation. PBL can increase motivation and develop problem-solving skills [22, 24, 25].

The implementation of problem-based learning can improve students' metacognition and reasoning skills [26-28]. Although there are many studies investigating the effect of problem-based learning (PBL) on higher-order thinking skills, including metacognition, these studies are limited and have not analyzed the effect of PBL on metacognitive abilities in the conjecturing process in solving pattern generalization problems. Furthermore, this study makes a valuable contribution to the mathematics education literature, especially in terms of the application of PBL to metacognitive abilities in the student's conjecturing process. In this study, researchers tried to analyze differences in metacognitive abilities in the conjecturing process between students who learned through the PBL model and those who learned through the conventional learning models. Thus, this study aimed to answer the following research question:

RQ. Does problem-based learning have any significant effect on the metacognitive ability in the conjecturing process of junior high school students?

\section{Literature Review}

2.1. Problem-Based Learning. Problem-based learning (PBL) is a learning model that provides learning materials in a contextual and realistic manner. Problem-based learning (PBL) requires students to work in groups to solve realworld problems. PBL is a student-centered learning model which provides various real-life problems for the students [29]. PBL provides the right learning environment to improve students' metacognitive and scientific reasoning [27].

The use of PBL, especially in learning mathematics, is to develop effective thinking skills, problem-solving skills, and independent learning. PBL syntax can encourage students to develop critical and metacognitive thinking skills [26-28]. The process of problem-solving in learning requires thinking, analyzing, evaluating, and generating ideas, which in turn trigger metacognitive skills.

Problem-based learning has five syntaxes, namely (1) student orientation to the problem, (2) organizing students to learn, (3) guiding individual or group investigations, (4) developing and presenting work results, and (5) analyzing 
and evaluating problem-solving. The five stages in PBL, starting from giving problems and conducting investigations in groups to the stage of evaluating, can improve metacognitive abilities. PBL is a meaningful learning model that involves students in solving tasks so that it can improve students' metacognition and reasoning skills [26-28].

2.2. Metacognitive Ability. Higher-order thinking skills include critical, logical, reflective, metacognitive, and creative thinking. Metacognition includes awareness of one's thinking processes, self-monitoring, and application of heuristics and steps to thinking. Metacognition occurs when a person encounters an unknown problem, uncertainty, question, or dilemma. Metacognition can also be defined as the ability to think about what has been thought, which includes three activities, namely awareness, regulation, and evaluation [30].

Metacognition is an important component in learning that involves guiding and managing learning activities [31]. Several previous studies have reported that metacognitive abilities affect students' mathematical abilities [32, 33]. Learning that involves metacognitive activities can motivate students to think with logical reasons. Through metacognitive scaffolding, students build meaningful new insights, knowledge, and skills. Students in small groups can be motivated to overcome conflicts and contradictions that arise when discussions occur, and they build new, more appropriate knowledge.

Metacognitive activities are the main goal of learning. Metacognition is an important component and must be there in the learning process because metacognition is an ability that must be raised, starting in the initial, core, and final activities [34]. In the learning process, the ability to think the metacognitive strategies should be emphasized from the elementary levels to high school levels. Even Permendikbud No. 20/2016 enacted that the metacognitive aspect was one of the important components in the competency standards of Indonesia's basic education graduates.

Primary school students' metacognitive abilities are formed due to their habits and experiences that are often involved in problem-solving activities. Problem-solving can challenge children's understanding and involve them in thinking more [35]. Piaget, in his theory, also states that children's metacognitive abilities develop through their awareness that grows in various points of view and experiences of self-conflict. Students who often learn to control, monitor their progress, become aware of the relationship between new information and what is already known, plan, and choose strategies are able to lead to success in solving problems.

2.3. Conjecturing Process. The seven stages describe the inductive reasoning process from Cañadas and Castro as one type of conjecturing process, namely the empirical induction of finite numbers of discrete cases [36]. The term conjecturing process referred to in this study is the empirical induction-type conjecturing process from finite numbers to discrete cases. In their research, Cañadas et al. [17] analyzed the types and stages of the conjecturing process that are familiar in mathematics education, which is the result of the collaboration of four countries, namely Australia, Canada, Spain, and Ukraine.

Sutarto et al. [37] describe seven stages of the conjecturing process. Those are (1) observing cases is the initial activity carried out on certain cases of the problems presented, (2) organizing cases is an activity that involves using strategies to systematically organize objects and facilitate work in certain cases, (3) finding and predicting pattern is an activity when observing a repetitive and regular situation, and imagining that the pattern may apply to the next unknown problems, (4) formulating conjectures is the activity of making statements based on empirical facts, but with an element of doubt, (5) validating conjectures is an activity that done to justify the resulting conjecture based on certain cases but not in general, (6) generalizing conjecture is an activity about changing beliefs related to the resulting conjecture that the conjecture is generally valid, and (7) justifying generalization is an activity carried out to convince people in which the resulting conjecture is correct.

All in all, the main goal of educational systems is to educate individuals who know whether they are able to accomplish a task alone, who must recognize how to finish a task successfully, who are able to get better results, and who know which information should be utilized functionally in a problem situation, in other words individuals who know what to do. Various ways are created by PBL to solve problems; information learned in this manner is functional information and includes metacognitive processes utilizing information. Thus, boosting individuals' self-directed learning skills is of vital importance. The role of metacognitive thinking and using information becomes paramount as individuals endeavor to be self-directed learners. In fact, students first experience problem situations with self-directed learning sessions. Thus, developing learners' metacognitive awareness levels is essential because evaluating learners' existing knowledge of a situation is necessary. Reviewing the literature so far, it was revealed that PBL has a relatively more significant impact on augmenting learners' metacognitive awareness levels compared with the traditional teaching methods. In the review of the literature, a few studies can be found that examine the effects of PBL on students' metacognitive awareness levels, but these studies are restricted to primary school learners and college undergraduates. However, this study examined the impact of PBL on the metacognitive awareness levels of junior high school students. This study is also valuable because it compared the impacts of PBL on students in the conjecturing process.

\section{Method}

3.1. Population and Sample. This research was conducted in the even semester of the 2020/2021 academic year on the pattern topic material. The population of this study is the eighth-grade students of MTs. The population of this study was the eight-grade students of MTs in West Mataram City 
of Indonesia. This study applies cluster sampling by randomly selecting two classes, resulting in one experimental class with a total of 30 students who are taught using PBL. The control class is subjected to conventional learning in which there are 30 students.

3.2. Research Design. This study employs a mixed-methods design, which is a combination of quantitative and qualitative methods. The quantitative method aims to analyze the data taken from the metacognitive ability test in the students' conjecturing process after applying the PBL. Furthermore, the qualitative method aims to analyze the data collected using tests and interviews with selected students. To find out the effect of PBL implementation, all students in the experimental group were observed and several students to be interviewed about their process of solving pattern generalization problems (number pattern material topics) were selected. This study investigated two variables, consisting of the application of PBL as an independent variable and a test of metacognitive abilities in the students' conjecturing process as the dependent variable.

The PBL stages in this study applied five stages. Those are as follows: (1) student orientation to the problem, (2) organizing students to learn, (3) guiding individual and group investigations, (4) developing and presenting the work, and (5) analyzing and evaluating problem-solving. In this study, the conventional teaching model is to transfer knowledge from teacher to students, which usually starts with the teacher's brief explanation of the fraction material and continues with students trying to answer some problems in the book or problems from the teacher and ends with a presentation of answers. The characteristics of the conventional teaching model are the tendency to dominate teaching activities, the transfer of knowledge from teachers to students, learning activities that tend to be monotonous, one-way communication, lots of practice in problem-solving, and teacher-centered teaching.

The experimental design of this study was to prepare two groups, namely, the experimental class and the control class, which were selected by purposive random sampling and examined by pre-test and post-test using a design as shown in Table 1 as follows.

Table 1 shows that $\mathrm{A}$ is the experimental group applying PBL and $B$ represents the control group applying conventional learning. $\mathrm{O} 1$ and $\mathrm{O} 3$ are the two groups that are at the same metacognitive ability and are tested using a pre-test. $\mathrm{O} 2$ is the result of the experimental group, while $\mathrm{O} 4$ is the result of the control group. In this study, the effect of treatment is analyzed using the $t$-test. Figure 1 shows the triangulation mode in which qualitative data are triangulated with quantitative data to determine the effect of PBL in improving students' metacognitive abilities in solving pattern problems.

3.3. Experimental Procedure. Experiments were carried out for six periods of mathematics learning, excluding pre-test and post-test. The first step was to prepare two groups, namely the experimental class and the control class, which were selected by purposive random sampling. There were two groups being investigated: class $\mathrm{A}$ as the experimental group and applied PBL and class $\mathrm{B}$ as the control group and applied conventional learning. The second step was giving a pre-test to each group, namely experiment and control.

The third step is the validation process. There are two mathematics education experts who validate the PBL lesson plans, student worksheets, and pre-test and post-test questions. The fourth step is the treatment process. In this step, the researcher acts as a teacher. In the experimental class, students are involved in PBL activities. In the control class, students are taught using conventional learning. The fifth step is giving a post-test. In this step, the researcher analyzes metacognitive abilities in the students' conjecturing process.

3.4. Instruments. Data were collected using research instruments in the form of lesson plans with problem-based learning methods, student worksheets, pattern generalization problem-solving tests, and interviews. Pattern generalization problem-solving tests are used to collect data on metacognitive abilities in the students' conjecturing process. The interview is carried out in an unstructured interview to understand and deepen metacognitive abilities in the conjecturing process of students in solving pattern generalization problems.

Pattern generalization problems are problems related to metacognitive abilities, and the problems applied are problems that can explore the students' conjecturing process [13]. Indicators and descriptions of metacognitive skills can be seen in Figure 2. The metacognitive skill rubric consisted of seven scales ( $0-5)$, which includes (1) the answer in his own words, (2) the order of a coherent answer, (3) the grammar or language, (4) the reason (analysis or evaluation and creation), and (5) answer (right/less/not really/blank) [24]. It is worth mentioning that the validity of the instruments was checked by a panel of experts who were mathematics education experts with 15 years of experience in teaching at different universities. Moreover, the reliability of the pre-test and post-test was computed through Cronbach's alpha formula and it was 0.88 and 0.91 , respectively.

3.5. Data Analysis. Students in the experimental and control groups are given problem-solving questions about the pattern material during the pre-test and posttest. Qualitative data are collected through unstructured interviews based on student task results during the post-test. The statistics used are descriptive and inferential statistics to analyze quantitative data. Descriptive statistics are used to show the mean and standard deviation, while the independent-samples $t$-test inferential statistics are used to test the effectiveness of PBL between the experimental class and the control class. The level of significance used to compare the average scores of the experimental and control classes is $5 \%$. 
TABLE 1: Equivalent pre-test and post-test control group design.

\begin{tabular}{lccc}
\hline Group & Pre-test & Treatment & Post-test \\
\hline $\mathrm{A}(n=30)$ & O1 & $\mathrm{X}$ & O2 \\
$\mathrm{B}(n=30)$ & $\mathrm{O} 3$ & - & $\mathrm{O} 4$ \\
\hline
\end{tabular}

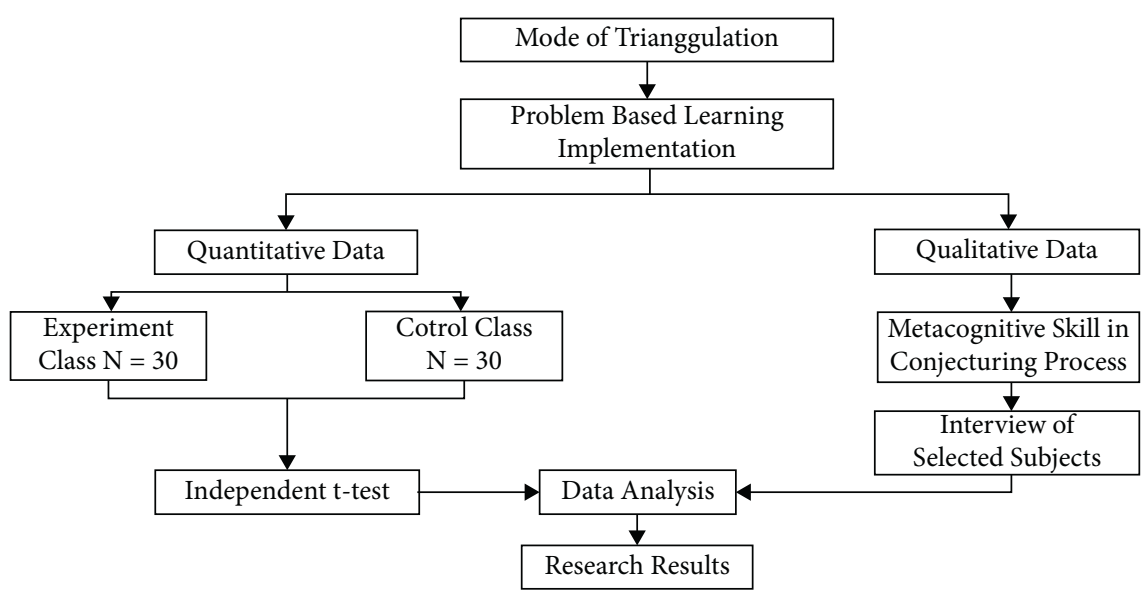

Figure 1: Mode of triangulation.

\begin{tabular}{|c|c|c|}
\hline No & Indicator & Description \\
\hline 1 & Plan & $\begin{array}{l}\text { - Setting goals (P1) } \\
\text { - Enabling relevant resources (P2) } \\
\text { - Choosing the right strategy (P3) }\end{array}$ \\
\hline 2 & Evaluation & $\begin{array}{l}\text { - Determine the level of understanding of a person (E1) } \\
\text { - How to choose the right strategy (E2) }\end{array}$ \\
\hline 3 & Monitoring & $\begin{array}{l}\text { - Checking one's progress (M1) } \\
\text { - Choose the appropriate improvement strategies } \\
\text { when the chosen strategy does not work. (M2) }\end{array}$ \\
\hline
\end{tabular}

FIGURE 2: Indicators and descriptions of metacognitive skills.

\section{Finding}

Based on the results of interviews and students' achievement, the percentage of students who carry out the indicators of metacognitive skills during the post-test can be shown in Figure 3.

More specifically related to the percentage of students who carry out indicators of metacognitive abilities in the conjecturing process of students in solving pattern generalization problems can be shown in Figure 4.

Before further analysis, this study is necessary to do a normality test. The number of respondents was 60 students. This shows that the pre-test results of the two classes, both the experimental class and the control class, are equal or not significantly different. It can be seen in Table 2 . Based on the information presented in Table 2, there was no statistically significant difference in the pre-test scores for the experiment class $(M=1.56, S D=.77)$ and the control class $(M=1.53, S D=.68, t(58)=.17, p=0.86)$. This conclusion was made since the $p$ value was larger than the significance level $(p>0.05)$. Hence, it could be inferred that the learners in the two groups were at the same level before treatment.

Table 3 revealed that there was a statistically significant difference between the post-test scores of the experiment class $(M=4.36, S D=1.09)$ and the control class $(M=2.63$, $S D=1.12)$ since the $p$ value under the Sig. (2-tailed) column was smaller than the significance level $(p<0.05)$. This shows that the two classes have differences in metacognitive abilities in the conjecturing process in solving pattern generalization problems after the application of PBL. Based on these results, it can be concluded that PBL had a significant effect on increasing metacognitive abilities in the conjecturing process.

Based on the results of students' answers in solving pattern generalization problems, data were obtained about metacognitive abilities in the students' conjecturing process. In the experimental class, metacognitive activities appear when students solve generalization pattern 


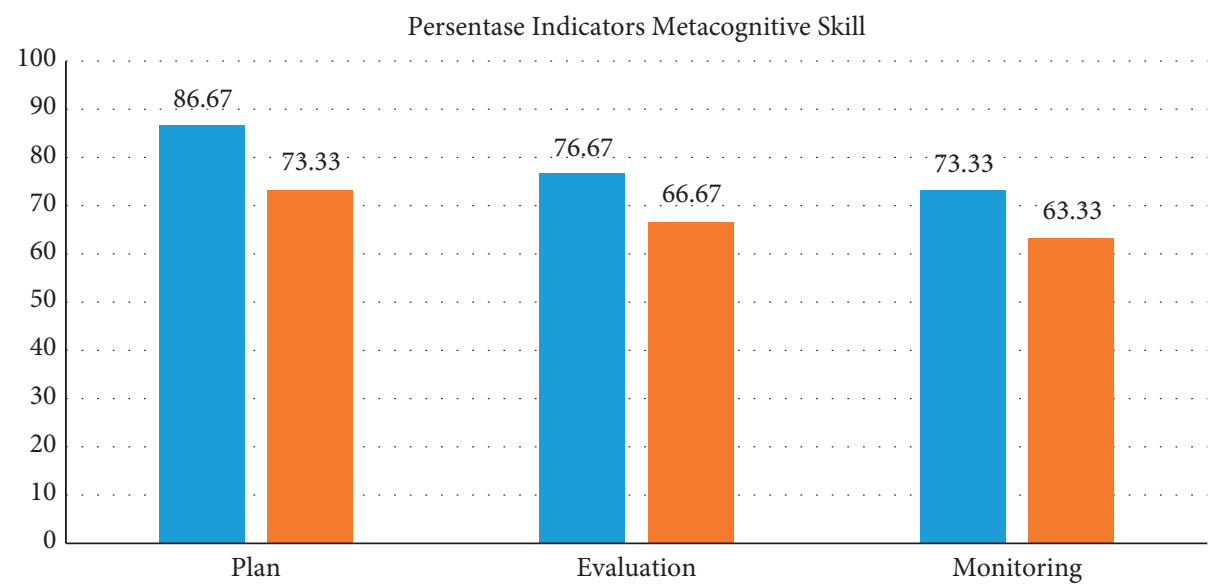

Eksperiment Class

Control Class

Figure 3: Percentages of metacognitive skill indicators.

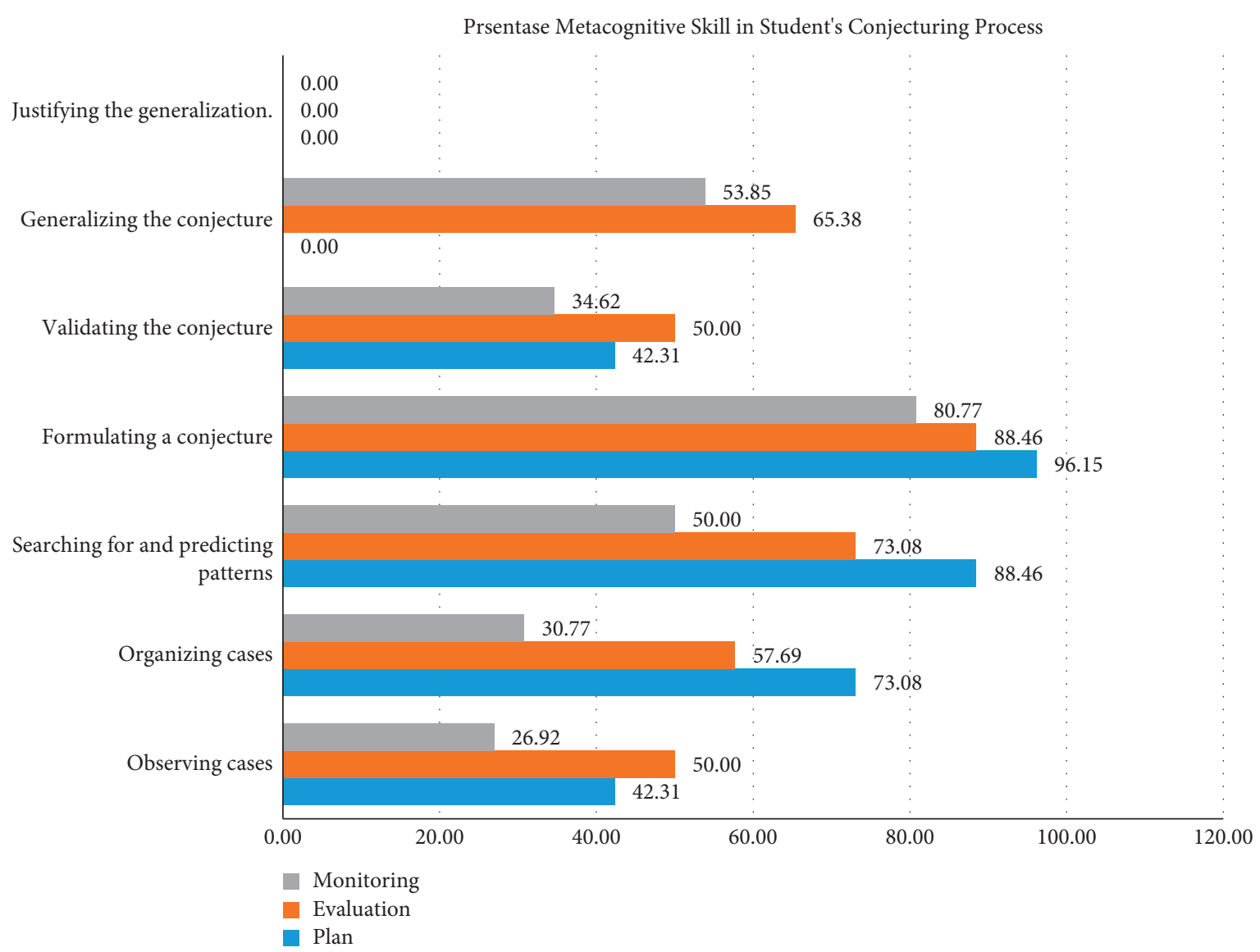

FIGURE 4: Percentages of metacognitive skill indicators on conjecturing process.

TABLE 2: Independent-samples $t$-test (pre-test of control class and experimental class).

\begin{tabular}{lccccc}
\hline & Group & $N$ & Mean & Std. deviation & $t$ \\
\hline Pre-test & Experiment class & 30 & 1.56 & 0.77 & 0.17 \\
& Control class & 30 & 1.53 & 0.68 & \\
\hline
\end{tabular}

TABLE 3: Independent-samples $t$-test (post-test of control class and experimental class).

\begin{tabular}{lccccc}
\hline & Group & $N$ & Mean & Std. deviation & $t$ \\
\hline Pre-test & Experiment class & 30 & 4.36 & 1.09 & $6.02^{*}$ \\
& Control class & 30 & 2.63 & 1.12 & \\
\hline${ }^{*} p<0.05$. & & & & &
\end{tabular}




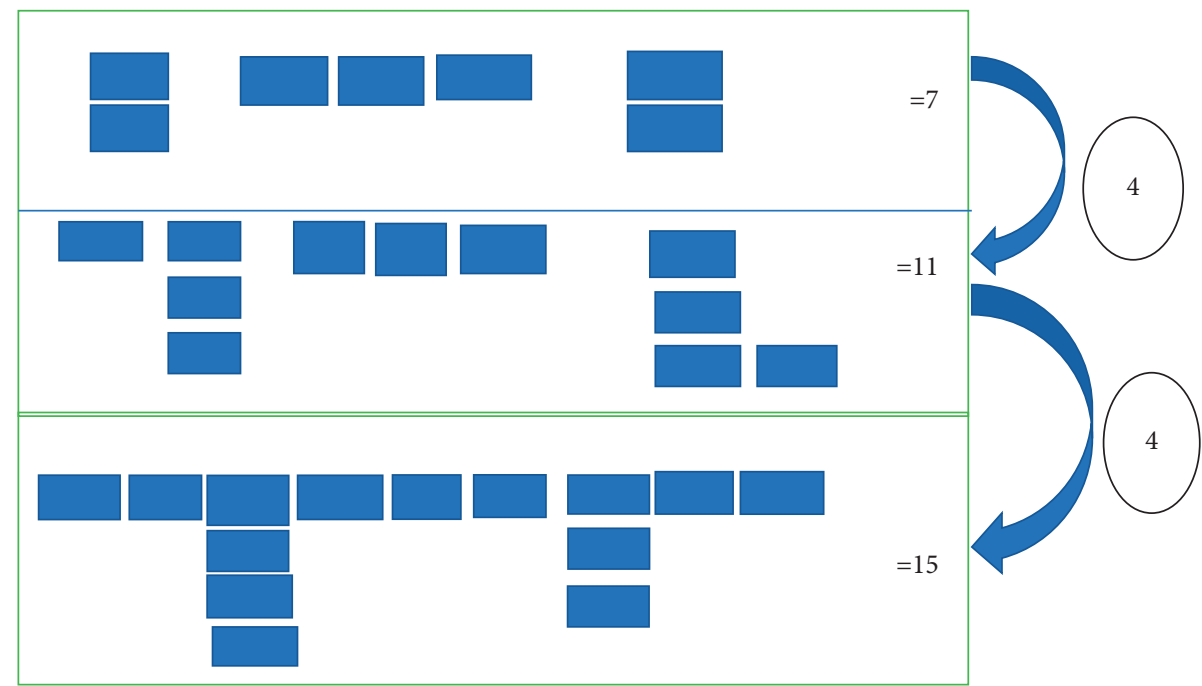

Figure 5: Work results of S1 subject in formulating conjectures.

problems. The following describes the metacognitive activities carried out by S1 based on the stages of the conjecturing process.

In generalizing the general formula conjecture to determine the number of squares in the image of n-unit, the $\mathrm{S} 1$ subject observes cases by observing and counting the number of squares separately based on the proximity factor, without distinguishing black and white squares.

$P$ : what is the first time you think after reading this matter?

S1: this is a black and white square pattern. At first, I counted. In the 1st image, there were 7 , the 2 nd image was 11 , and the 3 rd image was 15 . At first, I was confused about what to do with this pattern, but then I saw that the 1st image consisted of $1,1,3,1,1$. The 2 nd picture consists of $2,2,3,2,2$, and the 3rd picture consists of $3,3,3,3,3$

(Plan)

In the next stage, the S1 subject looks for and predicts patterns by paying attention to the addition of the 1 st image, 2 nd image, $3 \mathrm{rd}$ image, and thinking of the next image. In the 1st image to the 2 nd image, the increment of 4 , the 2 nd image to the $3 \mathrm{rd}$ image the increment of 4 and think that the next image also increases 4 .

$P:$ after seeing the 1 st picture consists of $1,1,3,1,1$, and so on, what do you do?

S1: I see the difference. But after I knew the difference, I could no't find the formula yet, finally, I focused on the 1 st image consisting of $1,1,3,1,1$. The 2 nd image consisted of 2, 2, 3, 2, 2, and 3rd picture consists of $3,3,3$, 3, 3

\section{(monitoring)}

$P$ : Then what next
S1: Well, if we look at these three pictures, each square in the 1st, 2nd, and 3rd pictures has the difference 4, as well as the next picture, the 4th image, consisting of $4+4+3+4+4$, the result is 19 . (evaluation)

This is also reinforced by the work of the S1 subject in finding and predicting patterns in Figure 5.

At the stage of formulating the conjecture, the S1 subject pays attention to the patterns obtained in the pattern search and prediction stage by producing a general formula conjecture to determine the number of squares in the figure $n-t h=n+n+n+n+3=4 n+3$. Furthermore, the $\mathrm{S} 1$ subject validated the conjecture with the 1 st, 2 nd, and 3 rd images. For the first image, the rule " $4 \times 1+3=7$ " is correct; for the second image, the rule " $4 \times 2+3=11$ " is correct; for the third image, the rule " $4 \times 3+3=15$ " is correct, and for the forth image, the rule " $4 \times 4+3=19$ " is correct. Following are excerpts of interviews with $\mathrm{S} 1$ subject.

$P$ : after getting the pattern, what do you do?

S1: from the pattern, I saw a pattern that was formed $P$ : what pattern do you mean?

S1: the pattern is like this Sir,

First image: $1+1+1+1+3=7$

First image: $2+2+2+2+3=11$

First image: $3+3+3+3+3=15$

From this pattern I made the general formula.

The image of $n$-unit: $n+n+n+n+3=4 n+3$ (evaluation)

Then, in the formula of $4 n+3$, when $n$ is substituted with 1 , the sum is 7 , when $n$ is substituted with 2 , the sum is 11 , and when $n$ is substituted with 3 and 4 , the sum is 15 and 19 , respectively.

This is also reinforced by the work of the S4 subject in formulating the conjecture in Figure 6 as follows. 


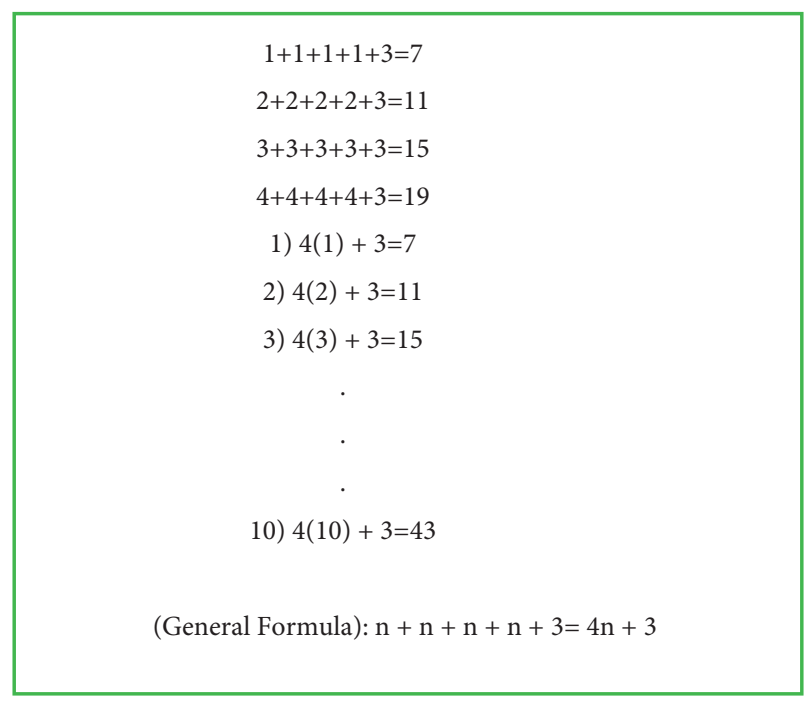

FIGURE 6: Concluding formula of S1 subject in formulating conjectures.

In the next stage, the $\mathrm{S} 1$ subject believes that the general formula for determining the number of squares in the nth image of the formed pattern is $4 n+3$. S1 subject believes in the general formula produced after validating. By believing in this general formula, the $\mathrm{S} 1$ subject has generalized the resulting general conjecture or formula. Following are excerpts of interviews with researchers and S1 subject.

$P$ : are you sure or not with this formula that you got?

S1: I am sure sir, because I have tested it (monitoring)

Furthermore, in justifying generalizations, the $\mathrm{S} 1$ subject shows certain examples as has been done when validating conjectures.

\section{Discussion and Conclusion}

The PBL model affects students' metacognitive abilities in the conjecturing process. The learning activities of the PBL model are able to bring up aspects of metacognitive abilities. The PBL stages in this study used five stages: (1) student orientation to the problem, (2) organizing students to learn, (3) guiding individual and group investigations, (4) developing and presenting the work, and (5) analyzing and evaluating problem-solving.

At the orientation stage of the problem, the teacher conveys a contextual problem going to be solved in groups. At this stage, the problem given is related to pattern generalization. Before entering the material, students receive information about the basic competencies and learning objectives to be gained, the scope of the material, learning steps, and the PBL model steps. Most of the interactions that occur at the orientation stage are interactions between students and teachers (the researcher himself), where the activity of preparing students physically and psychologically through apperception and giving problems can also encourage the emergence of metacognitive activities. Elbers also states that interactions in classroom learning encourage the reflection process [38].

At the stage of organizing students to learn, students are given problems about the generalization of patterns. The teacher divided the students into groups of 3-4 people and asked them to study all the instructions on the worksheets. At this stage, the teacher ensures that each member of the group understands their respective assignments. Each group is facilitated with student worksheets. The use of student worksheets aims to lead students to solutions. Instructions or steps for the discovery activity are listed in the student worksheets. In line with the Ellwood and Abrams research, student interaction, especially in group discussions, provides mutual feedback and increases students' motivation and achievement [39]. The characteristics of the experimental students who were given a problem-based learning model were more active and motivated to solve problems than the control class [19].

At the phase of guiding individual or group investigations, the teacher encourages students to collect appropriate information, conduct experiments, and solve problems. At this stage, many questioning activities appear, in group members, such as students asking how to predict the next pattern and formulate a general form of the pattern. Students ask each other from their groups, and even students ask the teacher. After students have been questioned, students make a hypothesis about how to find the formula and general form of the pattern. At this stage, there were several obstacles experienced by researchers, such as students' lack of literacy skills, students asking the teacher more than reading, and finding out on their own. However, the teacher still familiarizes students to read repeatedly and understand the worksheets given from the first to the last meeting so that students can practice students' literacy skills. The interactions that occur at this stage are interactions between students and students, students with learning resources (student worksheets), and students and teachers (researchers themselves), where this interaction encourages the emergence of metacognitive activities. Metacognitive activities arise, when students learn to question and evaluate the opinions of friends in the group. It is in line with Hastuti [30], who informs that the group discussion process can construct students' knowledge and strategies so that it can help students learn and evaluate strategies and trigger metacognitive abilities. Student social interactions that occur in PBL, such as engaging in discussions, questioning, and analyzing ideas, can improve critical and metacognitive thinking skills $[26,27]$.

Furthermore, at the stage of developing and presenting the work, the teacher monitors the discussion and guides the preparation of a report so that each group's work is ready to be presented. At this stage, students feel enthusiastic and motivated by a sense of curiosity to find all solutions so that they can be presented optimally. Based on the results of observations and interviews, students are more enthusiastic about learning because they feel more involved in the discovery activities contained in the student worksheets. In line with the findings of Sari, Sumarmi, Utomo, and Astina [18], giving problems provides motivation and challenges for 
students that serve as guidelines for finding solutions that require critical thinking.

Furthermore, at the phase of analyzing and evaluating the problem-solving process, each group made a presentation and the other group gave appreciation and input. Group 1 and group 3 provide input to group 2 because some incorrect answers are caused by not being careful in observing cases. The activity is continued by summarizing and making conclusions in accordance with the input obtained from other groups. At this stage, the students also concluded that to create a general formula, it was necessary to observe cases by counting the number of objects and organizing objects in tabular or sorted form. The patterns are danced and predicted by calculating differences and formulated general forms or formulas by paying attention to the formed patterns, validating general formulas with certain examples, and validating general formulas by testing them with certain examples as well. After being given the teacher's direction, they can conclude how to solve the pattern generalization problem.

Based on data analysis and findings, it can be concluded that problem-based learning $(\mathrm{PBL})$ has a significant effect on the metacognitive abilities of students' conjecturing process compared with the use of conventional learning models. Each stage in PBL is able to encourage students' metacognitive activities, especially when students are involved in group discussions. Like any other research study, this study has its own limitations. Due to some limitations, only 60 participants were included in this research. Next studies are offered to add more participants to their study samples to increase the generalizability of their findings. This study examined the effects of PBL on metacognitive abilities, and future studies can investigate the impacts of PBL on other psychological abilities. The other limitation refers to the period time of the treatment that was short, and next investigations can expand the treatment time. The study was limited to the Indonesian learners, and next studies can work on learners in geographical contexts. It is also suggested to future researchers to consider middle school teachers to apply technology-assisted PBL, especially in mathematical courses. In addition, it is suggested for future researchers to be able to apply PBL in other mathematical topics.

\section{Data Availability}

The data are available by direct contact with the corresponding author.

\section{Conflicts of Interest}

The authors declare that they have no conflicts of interest.

\section{Acknowledgments}

Researchers would like to thank the Ministry of Research and Technology or National Research and Innovation Agency, Deputy for Strengthening Research and Development, for assistance provided in applied research.

\section{References}

[1] W. Lestari, L. D. Pratama, and J. Jailani, "Metacognitive skills in mathematics problem solving," Jurnal Daya Matematis, vol. 6, no. 3, p. 286, 2019.

[2] A. T. Pratama, "Improving metacognitive skills using problem based learning (pbl) at natural science of primary school in deli serdang, Indonesia," Bios, vol. 11, no. 2, pp. 101-107, 2018.

[3] E. Darmawan, S. Zubaidah, S. Zubaidah, R. H. Ristanto, M. R. A. Zamzami, and B. Wahono, "Simas eric learning model (SELM): enhance student' metacognitive skill based on the academic level," International Journal of Instruction, vol. 13, no. 4, pp. 623-642, 2020.

[4] A. Kuzle, "Patterns of metacognitive behavior during mathematics problem-solving in a dynamic geometry environment," International Electronic Journal of Mathematics Education, vol. 8, no. 1, pp. 20-40, 2013.

[5] B. M. Nielsen, "Fostering learner autonomy in foreign language learning: justifications, Definitions,Misconceptions, and interrelated components for its realization," HOKUGA, vol. 8, no. 1, pp. 33-52, 2019.

[6] M. Bannert and C. Mengelkamp, "Assessment of metacognitive skills by means of instruction to think aloud and reflect when prompted. Does the verbalisation method affect learning?" Metacognition and Learning, vol. 3, no. 1, pp. 39-58, 2008.

[7] L. Dörr and F. Perels, "Improving metacognitive abilities as an important prerequisite for self-regulated learning in preschool children," Lnternational Electronic Journal of Elementary Education, vol. 11, no. 5, pp. 449-459, 2019.

[8] L. W. Anderson and D. R. Krathwohl, A Taxonomy for Learning, Teaching, and Assessing: A Revision of Bloom's Taxonomy of Educational Objectives, Pearson, London, UK, 2001.

[9] I. D. Hastuti, S. Surahmat, and Dafik, "The effect of guided inquiry learning in improving metacognitive skill of elementary school students," International Journal of Instruction, vol. 13, no. 4, 2020.

[10] I. Hastuti, S. Surahmat, and Dafik, "Development of collaborative inquiry-based learning model to improve elementary school students' metacognitive ability," International Journal of Scientific and Technology Research, vol. 9, no. 2, pp. 1240-1247, 2020a.

[11] S. Suhirman, S. Prayogi, S. Prayogi, and M. Asy'ari, "Problembased learning with character-emphasis and naturalist intelligence: examining students critical thinking and curiosity," International Journal of Instruction, vol. 14, no. 2, pp. 217-232, 2021.

[12] T. Suratno, "Lesson study in Indonesia: an Indonesia university of education experience," International Journal for Lesson and Learning Studies, vol. 1, 2012.

[13] D. Sutarto, I. D. Hastuti, and Surahmat, "An analysis of students' difficulties in conjecturing process of block paving problems," Journal of Physics: Conference Series, vol. 1465, no. $1,2020$.

[14] D. Sutarto, I. D. Hastuti, and Surahmat, "The effectiveness of problem-based learning to improve students' conjecturing ability in solving block-paving problems," International Journal of Scientific and Technology Research, vol. 8, no. 10, 2019.

[15] J. Dindyal, "High school students' use of patterns and generalisations," Proceedings of the 30th Annual Conferences of the Mathematics Education Research Group of Australasia, vol. 1, pp. 236-245, 2007. 
[16] D. Küchemann, "Using patterns generically to see structure," Pedagogies: International Journal, vol. 5, no. 3, pp. 233-250, 2010.

[17] M. C. Cañadas, J. Deulofeu, L. Figueiras, D. Reid, and O. Yevdokimov, "The conjecturing process: perspectives in theory and implications in practice," Journal of Teaching and Learning, vol. 5, no. 1, 2007.

[18] Y. I. Sari, S. Sumarmi, D. H. Utomo, and I. K. Astina, "The effect of problem based learning on problem solving and scientific writing skills," International Journal of Instruction, vol. 14, no. 2, pp. 11-26, 2021.

[19] N. Suryanti and Nurhuda, "The effect of problem-based learning with an analytical rubric on the development of students' critical thinking skills," International Journal of Instruction, vol. 14, no. 2, pp. 665-684, 2021.

[20] A. A. Aldarmahi, "The impact of problem based learning versus conventional education on students in the aspect of clinical reasoning and problem solving," Education in Medicine Journal, vol. 8, no. 3, pp. 1-10, 2016.

[21] S. Moody, X. Hu, L. J. Kuo, M. Jouhar, Z. Xu, and S. Lee, "Vocabulary instruction: a critical analysis of theories, research, and practice," Education Sciences, vol. 8, no. 4, 2018.

[22] A. S. Argaw, B. B. Haile, B. T. Ayalew, and S. G. Kuma, "The effect of problem based learning (PBL) instruction on students' motivation and problem solving skills of physics," Eurasia Journal of Mathematics, Science and Technology Education, vol. 13, no. 3, pp. 857-871, 2017.

[23] P. Michael, "Does active learning work ? A review of the research," Journal of Engineering Education, vol. 93, pp. 223-231, 2004.

[24] B. Sugiharto, A. D. Corebima, A. D. Corebima, H. Susilo, and I. Ibrohim, "The pre-service biology teacher readiness in blended collaborative problem based learning (BCPBL)," International Journal of Instruction, vol. 12, no. 4, pp. 113-130, 2019.

[25] S. K. Taradi, M. Taradi, K. Radić, and N. Pokrajac, "Blending problem-based learning with Web technology positively impacts student learning outcomes in acid-base physiology," Advances in Physiology Education, vol. 29, no. 1, pp. 35-39, 2005.

[26] N. W. Ashari and S. Salwah, "Problem based learning (PBL) dalam meningkatkan kecakapan pembuktian matematis mahasiswa calon guru," JMPM: Jurnal Matematika Dan Pendidikan Matematika, vol. 2, no. 2, p. 100, 2017.

[27] S. Haryani, Masfufah, N. Wijayati, and C. Kurniawan, "Improvement of metacognitive skills and students' reasoning ability through problem-based learning," Journal of Physics: Conference Series, vol. 983, no. 1, 2018.

[28] C. Tosun and E. Senocak, "The effects of problem-based learning on metacognitive awareness and attitudes toward chemistry of prospective teachers with different academic backgrounds recommended citation tosun, cemal and senocak, erdal (2013) "the effects of problem-based learning," Australian Journal of Teacher Education, vol. 38, no. 3, pp. 61-73, 2013.

[29] M. Maulidiya and E. Nurlaelah, "The effect of problem based learning on critical thinking ability in mathematics education," Journal of Physics: Conference Series, vol. 1157, no. 4, 2019.

[30] I. Hastuti, S. Surahmat, and Dafik, "Shifting of perfective metacognitive activities in solve math problems," Journal of Physics: Conference Series, vol. 1465, no. 1, 2020 b.
[31] M. Radovan, "Cognitive and metacognitive aspects of key competency "learning to learn"," Pedagogika, vol. 133, no. 1, pp. 28-42, 2019.

[32] S. J. Pape, C. V. Bell, and İ. Yetkin, "Developing mathematical thinking and self-regulated learning: a teaching experiment in a seventh-grade mathematics classroom," Educational Studies in Mathematics, vol. 53, no. 3, pp. 179-202, 2003.

[33] A. Yenilmez, S. Sungur, and C. Tekkaya, "Investigating students' logical thinking abilities: the effects of gender and grade level," Hacettepe University Journal of Education, vol. 28, pp. 219-225, 2005.

[34] W. Ya-Hui, "A study on metacognition of college teachers," The Journal of Human Resource and Adult Learning, vol. 8, no. 1, pp. 80-91, 2012.

[35] I. D. Hastuti, T. Nusantara, and H. Susanto, "Constructive metacognitive activity shift in mathematical problem solving," Educational Research and Reviews, vol. 11, no. 8, pp. 656-667, 2016.

[36] M. C. Cañadas and E. Castro, "A proposal of categorisation for analysing inductive reasoning," $P N A$, vol. 1, no. 2, pp. 67-78, 2007.

[37] S. Sutarto, I. D. Hastuti, and H. Haifaturrahmah, "Analisis kemampuan metakognisi mahasiswa PGSD dalam menyelesaikan masalah matematika," JPIn: Jurnal Pendidik Indonesia, vol. 3, no. 1, pp. 61-71, 2020.

[38] E. Elbers, "Classroom interaction as reflection: learning and teaching mathematics in a community of inquiry," Educational Studies in Mathematics, vol. 54, no. 1, pp. 77-99, 2003.

[39] R. Ellwood and E. Abrams, "Student's social interaction in inquiry-based science education: how experiences of flow can increase motivation and achievement," Cultural Studies of Science Education, vol. 13, 2018. 